\title{
When less is more: maximum safe levels for vitamins and minerals in food supplements across the $\mathrm{EU}$
}

\author{
O.C. Lyons ${ }^{1,2}$, S. O’Mahony ${ }^{1}$, C.B. O’Donovan ${ }^{1}$, C.M. Donovan ${ }^{1}$, C. Geraghty ${ }^{1}$, \\ S. Taleghani ${ }^{1}$ and M.A.T. Flynn ${ }^{1,2}$ \\ ${ }^{1}$ Food Safety Authority of Ireland, Dublin 1, Republic of Ireland and ${ }^{2}$ Nutrition Innovation Centre for Food and \\ Health, Ulster University, Coleraine, BT52 1SA, UK.
}

EU food law harmonises rules across Member States (EU MS) for consumer protection and free movement of goods. Directive 2002/ 46/EC regulates food supplements to ensure potent and bioavailable forms of vitamins and minerals are used but has yet to establish maximum safe levels (MSLs) ${ }^{(1)}$. To address excessive levels in food supplements, the Food Safety Authority of Ireland (FSAI), considered all vitamins and minerals allowed in food (n30) and has developed a report for industry providing guidance on establishing MSLs $^{(2)}$. Following a review of tolerable upper intake levels (ULs; highest daily amount of nutrient intake from all sources) established by recognised authoritative scientific bodies, this report adopts ULs for Ireland, which vary according to age, for 21 nutrients. According to the report, the amount of these 21 nutrients in food supplements, when combined with dietary intakes from other foods of high consumers $\left(95^{\text {th }}\right.$ percentile) within each age group, should not exceed the ULs set. The aim of this study is to examine MSLs established by other EU MS for nutrients in food supplements most commonly requiring risk assessment in Ireland.

EU MS (n28) were contacted through their competent authorities and asked for information on MSLs for vitamins and minerals in foods supplements established at national level. Specific information was requested on whether such MSLs were guidance or legally binding; nutrients the MSLs apply to; and whether they vary according to age. Responses were compared considering EU principles of harmonisation and consumer protection regarding vitamins and minerals most commonly requiring risk assessments in $2016-2017$.

Responses were received from 15 EU MS, 10 of which have established MSLs at national level (four in legislation and six in guidance) and five have no MSLs. No responses were received from 13 EU MS. In Ireland during 2016 and 2017, of a total of 88 food supplement risk assessments, $21 \%$ concerned vitamin D, 16\% vitamin B6, 10\% folic acid, 10\% vitamin A and 5\% magnesium. The table below outlines adult or population MSLs where applicable, established for these nutrients by 10 EU MS compared to the Irish UL.

\begin{tabular}{|c|c|c|c|c|c|}
\hline EU Member State & $\begin{array}{c}\text { Vitamin D } \\
(\mu \mathrm{g} / \mathrm{d})\end{array}$ & $\begin{array}{c}\text { Vitamin B6 } \\
(\mathrm{mg} / \mathrm{d})\end{array}$ & $\begin{array}{c}\text { Folic Acid } \\
(\mu \mathrm{g} / \mathrm{d})\end{array}$ & $\begin{array}{l}\text { Vitamin A } \\
(\mu \mathrm{g} \mathrm{RE} / \mathrm{d})\end{array}$ & $\begin{array}{c}\text { Magnesium } \\
(\mathrm{mg} / \mathrm{d})\end{array}$ \\
\hline Ireland* & 100 & 25 & 1000 & 3000 & 250 \\
\hline Germany* & 100 & 20 & 800 & 3000 & 250 \\
\hline Netherlands ${ }^{\dagger}$ & 75 & 21 & N/A & 1200 & N/A \\
\hline Belgium $^{\S}$ & 75 & 6 & 500 & 1200 & 450 \\
\hline Luxembourg $^{\S}$ & $7 \cdot 5$ & $4 \cdot 2$ & 400 & 1200 & $562 \cdot 5$ \\
\hline $\mathrm{UK}^{\S}$ & N/A & $10 \& 100$ & N/A & N/A & 400 \\
\hline France $^{\dagger}$ & 50 & $12 \cdot 5$ & 500 & 800 & 360 \\
\hline Estonia $^{\dagger}$ & 100 & 25 & 1000 & 3000 & 250 \\
\hline Slovenia $^{\dagger}$ & 20 & 8 & 400 & 1500 & 600 \\
\hline Italy $^{\S}$ & 50 & 9.5 & 400 & 1250 & 450 \\
\hline Denmark $^{\dagger}$ & 95 & 14 & 600 & 890 & 233 \\
\hline
\end{tabular}

${ }^{*}$ Adult UL; ${ }^{\dagger}$ Adult MSLs in EU MS having several MSLs for age (2-8); ${ }^{\dagger}$ Single MSLs for $\geq 15$ years; ${ }^{\S}$ Single MSLs for whole population; MSLs set in national legislation are in bold; all remaining are guidance values.

As shown in the table, there is substantial variation in MSLs across EU MS for those vitamins and minerals in food supplements that commonly require risk assessment in Ireland. This variation includes actual levels of MSLs, age ranges they apply to and legal basis. This undermines MSLs, complicates risk communication to consumers and makes the trade environment very challenging.

In conclusion, harmonisation of MSLs for vitamins and minerals in food supplements through EU law is urgently needed. In addition to consumer protection this would provide clarity for trade and highlight for consumers that 'less is more' in the case of vitamin and mineral food supplements.

1. European Commission (2002) Directive 2002/46/EC available from https://www.fsai.ie/uploadedFiles/Science_and_Health/Directive-2002-46-ECon-food-supplements.pdf

2. Food Safety Authority of Ireland (In Press) The Safety of Vitamins and Minerals in Food Supplements - Establishing Tolerable Upper Intake Levels and a Risk Assessment Approach for Products Marketed in Ireland - A Report of the Scientific Committee. 